\title{
Microhistoria del turismo falangista. Agencia, caridad y privilegios en el segundo franquismo*
}

\author{
José Luis Aguilar López-Barajas ${ }^{1}$ \\ Universidad Friedrich Schiller de Jena \\ Jose.aguilar.lopez-barajas@uni-jena.de
}

RESUMEN: Este artículo tiene como objetivo analizar la experiencia de las vacaciones con Educación y Descanso, así como el funcionamiento de esta Obra Sindical. Para ello, se usarán fuentes de archivo, especificamente, y dado que se trata de un estudio de caso, las cartas enviadas por un individuo para solicitar un puesto de vacaciones, que se verán complementadas por otros materiales que permiten, con las metodologías de la microhistoria y de la alltagsgeschichte o historiografía de la vida cotidiana, ilustrar un marco amplio del régimen franquista. Así, el núcleo del texto girará en torno a la experiencia de los individuos y su relación con el Movimiento, las respuestas que este dio a los nuevos retos que se le presentaban y los obstáculos que marcaron el poco éxito del proyecto de la Falange de Solís.

\section{Palabras clave: Educación y Descanso; microhistoria; vacaciones; experiencia.}

\section{Microhistory of Falangist tourism. Agency, Charity and Privileges in Second Francoism}

ABSTRACT: The article analyses the holiday experience with Educación y Descanso and its operations. For that purpose, it draws on archival sources, especially, in view of its case study, the letters sent by an individual applicant for a place on one such holiday. It is complemented by other archival material and uses microhistory methodologies and Alltagsgeschichte, or the historiography of everyday life, to shed a broad light on the Francoist

* Siglas de archivos: Archivo General de la Administración, Alcalá de Henares, Madrid (AGA); y Thuringisches Universität und Landesbibliothek, Jena, Turingia (THULB).

${ }^{1}$ ORCID iD: https://orcid.org/0000-0002-2177-3323

Copyright: (C) 2021 CSIC. Este es un artículo de acceso abierto distribuido bajo los términos de una licencia de uso y distribución Creative Commons Reconocimiento 4.0 Internacional (CC-BY 4.0) 
regime. At its essence, the text assesses the experience of individuals and their relationship with the Movimiento Nacional, how the National Movement responded to the new challenges it faced and the obstacles leading to the lack of success of Solis's Falange project.

KEY WORDS: Educación y Descanso; microhistory; holidays; experience.

CÓMO CITAR ESTE ARTÍCULO / CITATION: Aguilar López-Barajas, José Luis, «Microhistoria del turismo falangista. Agencia, caridad y privilegios en el segundo franquismo», Hispania, 81/269 (Madrid, 2021): 767-795. https://doi.org/10.3989/ hispania.2021.020.

\section{OBJETIVO, FUENTES Y METODOLOGÍA}

El propósito de este artículo es estudiar la forma en la que los ciudadanos de a pie experimentaban la política de vacaciones de Falange. Hasta ahora, el estudio de las vacaciones y el turismo en el régimen de Franco han sido enfocados desde el prisma de la recepción, esto es, de la «invasión pacífica» de europeos que llegó a partir de la década de los cincuenta ${ }^{2}$. Se han desarrollado enfoques cuantitativos muy centrados en la historia económica que muestran como el régimen modificó su rumbo gracias al turismo ${ }^{3}$. Por otro lado, se ha estudiado cómo este proceso se encuadró a nivel político en un tiempo nuevo para el franquismo, que reestructuró sus relaciones con Europa y también se vio afectado en su funcionamiento interno ${ }^{4}$. Este artículo se propone cambiar el foco y no centrarse en la economía y la política del régimen «desde arriba», ni en la llegada masiva de turistas. Por el contrario, pretendo acercarme a cómo este tiempo de cambio y expansión del turismo en el comienzo del llamado «segundo franquismo $»^{5}$ fue experimentado por los ciudadanos españoles y, en concreto, por aquellos que tomaron sus vacaciones con la Obra Sindical de Educación y Descanso.

A través de la investigación de los modos, las actitudes y comportamientos $y$, en definitiva, la experiencia vacacional de los sujetos, pretendo contribuir modestamente a la comprensión de eso que se ha dado en llamar las actitudes sociales en el franquismo y que, en las últimas décadas, ha aportado considerable luz al estudio de la sociedad bajo la dictadura ${ }^{6}$. Cuando se trabaja sobre un caso en el que interaccionan individuos e instituciones el objetivo ha de ser

2 PACK, 2006. GLASER, 2018.

3 PELLEJERO, 1999.

4 VELASCO, 2004. CRUMBAUGH, 2009. MORENO GARRIDO, 2007.

5 TOWNSON, 2009.

${ }^{6}$ HERNÁNDEZ, 2013. FUERTES, 2017. DEL ARCO, MARCO y HERNÁNDEZ, 2013. RODRÍGUEZ BARREIRA, 2007. SAZ, 1999. 
doble. Por un lado, ver la plasmación concreta y práctica de las políticas y en qué medida estas se ajustaban, o se alejaban, del plano teórico del que provenían. Por otro, ver de qué manera eran recibidas por los sujetos, cómo estos se relacionaban con ellas y cuál era su reacción, a priori y a posteriori, respecto a las instituciones responsables de dichas políticas. Las conclusiones que se derivan de este enfoque apuntan, en un sentido general, a una comprensión del momento histórico, entendido este no como la suma de los compartimentos estancos de la sociedad y el Estado, sino como la forma dinámica en que ambos interaccionaban y cómo ello daba carta de naturaleza al funcionamiento del sistema, por un lado, y a la experiencia de los individuos, por otro.

El trabajo se basa fundamentalmente en documentos de archivo, la materia prima del historiador sin la cual la aproximación al pasado no es posible. En concreto, voy a usar como columna vertebral una extensa carta escrita por un ciudadano madrileño de nombre Bonifacio García Duarte que, en el año 1959, accedió a los servicios de la Obra Sindical de Educación y Descanso. Lejos de componer un trabajo guiado por un solo documento, lo que la carta dispone me permite ramificar el tema central y abordar diversos aspectos relacionados con Educación y Descanso, sus dirigentes y sus beneficiarios, que contribuyen a una mayor comprensión de la implantación social de la obra sindical. Pero las fuentes en sí no tienen por qué conducir a nada, sino que es la interpretación y la óptica con la que se abordan las que arrojan conocimiento histórico. Así, una carta de un ciudadano corriente al jefe de la Obra Sindical puede pasar desapercibida para la mayoría de los historiadores si no se analiza a través de unas lentes específicas que parten de un conocimiento previo de lo que una fuente de este cariz puede aportar y de la lectura de muchas otras fuentes que apuntan en sentidos similares.

Del mismo modo, a pesar de ir pertrechados con una metodología y un bagaje teórico concreto, la fuente carece de sentido si no se complementa con otras, consultadas tanto antes como después, que posibilitan que la carta de García Duarte constituya un eje alrededor del cual cimentar una explicación historiográfica que dé cuenta de asuntos que en la carta son tanto latentes o velados como manifiestos. Así, se usarán muchas otras fuentes «desde abajo», esto es, que reflejan una experiencia individual con el servicio de vacaciones falangista y que matizan, discuten o contradicen lo escrito por García Duarte. En este sentido, las cartas que se van a utilizar proceden de la consulta extensiva de los fondos del Archivo General de la Administración, en el que se conserva toda la documentación relativa a Falange. Así, de manera análoga, prestaré atención a fuentes «desde arriba», que se corresponden con las ordenanzas de la Obra Sindical de Educación y Descanso, la correspondencia entre

\footnotetext{
${ }^{7}$ CENARRO, 2013: 29-44.
} 
sus miembros dirigentes y, de forma más general, con las directivas y normativas del régimen franquista. De manera que el texto es una combinación de fuentes de diversa índole, una de las cuales adquiere un carácter protagónico que guiará el análisis histórico que pretendo realizar.

Como apuntaba, es la metodología la que lleva a un historiador a interesarse por un personaje de nula relevancia pública y de escasa o dudosa representatividad - en el caso de que se le quiera tomar como una media aritmética perfecta de cómo los ciudadanos de a pie experimentaban las vacaciones-. He desechado interpretaciones en este sentido ya que pueden ser confusas y se alejan del objetivo del texto, a la par de lo arriesgado que sería establecer, sin datos sociológicos, que la experiencia de García Duarte se asemeja a la del sujeto medio bajo la dictadura. El anclaje teórico-metodológico del texto huye de generalizaciones de este tipo y adeuda planteamientos e ideas en diversos sentidos que poco tienen que ver con ellas. Por el contrario, el texto se nutre de un conglomerado de escuelas historiográficas que confluyen en la intersección de dos que conforman dos enfoques con similitudes que me permiten abordar un tema como el de este artículo con garantías. Me refiero a la Microhistoria y a la Alltagsgeschichte alemana o historia/experiencia de la vida cotidiana.

Mi lectura de la microhistoria se nutre de las propias aportaciones de historiadores como Giovanni Levi o Carlo Ginzburg, así como de la exégesis sobre la disciplina llevada a cabo por académicos españoles ${ }^{8}$. La cuestión que es útil para lo que aquí pretendo exponer es el hecho de que la microhistoria no es una cuestión de escala sino, sobre todo, de enfoque. La microhistoria no sustancializa casos concretos más o menos peculiares, sino que, a través de ellos, conforma un panorama que permite acceder a una comprensión dinámica del proceso histórico en el que la dialéctica entre los individuos y el Estado — cosa que en el artículo será importante- - lejos de estar prefigurada, es abierta y huye de interpretaciones unívocas y monocausales en las que el segundo subyuga a los primeros y determina sus formas de vida en todos los sentidos posibles. Quizás no soy muy original al referirme al Menocchio de Ginzburg como el ejemplo más claro de lo que la microhistoria pretende. La cosmovisión de este molinero friuliano del siglo XVI, aquella basada en un extraño queso del que salían y entraban gusanos, no estaba determinada por el pensamiento dominante católico de su zona. Tampoco su pensamiento guardaba estrecha relación con la reforma luterana, de la que algo pudo conocer. Ni siquiera era una copia de la teología anabaptista, con la que guardaba algunas semejanzas. La conclusión de Ginzburg es que la configuración del cosmos de un personaje como Menocchio es una miscelánea de muchas cosas, entre ellas la tradición popular que tan bien estudió Michail Bakhtin, que, en modo alguno, está determinada

8 PONS y SERNA, 2000. 
por un pensamiento ajeno, sino que surge de la interacción dinámica de las distintas esferas en las que el molinero se movía ${ }^{9}$. Así, la interpretación de la experiencia vacacional del ciudadano García Duarte no debe ser vista, a mi juicio, desde una óptica determinista, viendo detrás de cada uno de sus comentarios el influjo directo del totalitarismo franquista. Tampoco, y dadas las duras críticas que realiza contra la Obra Sindical de Educación y Descanso, podemos concluir que éstas vienen dadas por un antifranquismo incipiente, que se correspondería con las tesis del «retorno de la sociedad civil» ${ }^{10}$ que afirman que la sociedad española que hizo la transición a la democracia era una sociedad altamente democratizada y de valores liberales que había roto simbólicamente con el franquismo. Con esto se caería en la interpretación whig de la historia a la que tantos reparos pueden ponerse ${ }^{11}$. El análisis del texto, siguiendo la microhistoria, va a reconocer lo que desde la «historia desde abajo»y, particularmente, por parte de EP Thompson, se conoce como la agency, esto es, la agencia personal de los individuos para dotar de sentido a su pensamiento y sus acciones, que si bien no es un individualismo metodológico ya que reconoce, siguiendo a Marx, que el individuo hace su historia, pero en condiciones que él no ha elegido, lo libera de las constricciones a las que le había sometido la historia estructura ${ }^{12}$.

La agencia es probablemente la clave de bóveda en la que la microhistoria se encuentra con la Alltagsgeschichte alemana. Desarrollada en universidades como Essen y Berlín desde los años ochenta ${ }^{13}$, y con el referente, común con la microhistoria, de la «historia desde abajo», la Alltagsgeschichte colocó la experiencia del sujeto en un primer plano. El origen de algunas de estas investigaciones tuvo como objeto de estudio la vida y experiencia obrera tanto en el II Reich alemán como en el nazismo ${ }^{14}$. En un contexto historiográfico alemán en el que primaban las disputas por el camino especial de la nación, o «Sonderweg», de carácter estructural en las que el individuo no jugaba papel alguno ${ }^{15}$, la Alltagsgeschichte se propuso investigar las trayectorias vitales de los ciudadanos corrientes. Al igual que en la microhistoria, no se daba por supuesto que el Estado determinase la vida de los individuos, sino que pretendían dar a éstos una significación propia y una agencia que les permitiese crear un espacio en el que dotar de sentido su existencia ${ }^{16}$. Entre las aportaciones de la Alltagsgeschichte que considero relevantes para entender la experiencia

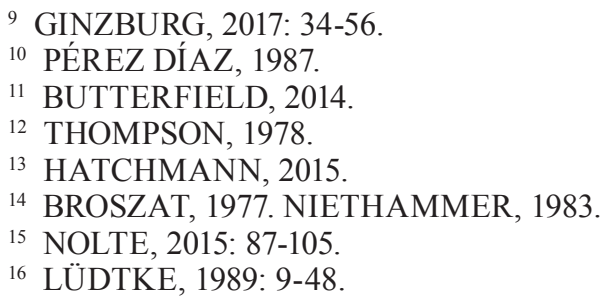


de García Duarte brilla con luz propia el concepto de Eigen-sinn ${ }^{17}$. Una de las diferencias entre esta escuela alemana y la microhistoria es la contemporaneidad de la primera, ya que se ha dedicado a estudiar en buena medida las dos dictaduras alemanas del siglo XX, mientras que el ámbito de actuación de la microhistoria ha estado más volcado a la Edad Moderna. El problema de estudiar las dictaduras de la pasada centuria estriba en que la cantidad de estudios, interpretaciones, fuentes orales y escritas, novelas o películas convierten el objeto en casi inabarcable. Existe, además, en las últimas décadas un polo historiográfico cuyo objeto de estudio son las resistencias a las dictaduras ${ }^{18}$, ámbito en el cual la Alltagsgeschichte debería tener algo que decir. El concepto de Eigen-sinn es aquí clave, porque tercia en el debate sobre la expansión del campo de las resistencias, desde lo que en alemán se conoce como Widerstand, esto es, resistencia armada, a la Resisten $z^{19}$, o resistencia cotidiana, que abarca un sinfín de métodos de no aceptación, disidencia o boicots cotidianos. El problema de estas resistencias silenciosas, infrapolíticas o microrresistencias, es que en ocasiones se sobreestima tanto el potencial que las mismas albergaban como su propia naturaleza. Una de las contribuciones que en las últimas décadas ha abundado en este sentido ha sido la del antropólogo James C. Scott, cuya interpretación adolece a mi modo de ver de estos problemas, ya que su enfoque de la infrapolítica como microrresistencia concibe las acciones cotidianas de los individuos, tales como la no aceptación de las consignas de la élite, de un modo no ajustado al sentido histórico que para los sujetos tuvieron. Para muestra un botón. Scott, citando a Le Roy Ladurie, aborda el tema del levantamiento en la ciudad francesa de Romans de 1580. Un levantamiento popular que se produjo por diversos motivos y que, para Scott, estuvo precedido por la infrapolítica de la que él habla:

El primer signo de conflicto fue el hecho de que el carnaval no siguió los canales tradicionales que le había asignado la élite (...) los artesanos y comerciantes se negaron, en esa ocasión, a participar en él, y realizaron sus propios desfiles en sus respectivos barrios ${ }^{20}$.

Para Scott, la distorsión del carnaval por parte de las clases populares no adquiere una entidad propia, sino que es la antesala del verdadero levantamiento. De este modo, establece una causalidad, muy discutible por otra parte, que vacía de sentido la acción y el comportamiento de los artesanos respecto al carnaval y la supedita a una acción mayor. La infrapolítica así vista, ado-

${ }^{17}$ LINDENBERGER, 1999: 14-15.

18 STEINBACH, 2004. KERSHAW, 2000. ORBACH, 2011.

19 BROSZAT, 1983: 11-25.

${ }^{20}$ SCOTT, 1990: 212-213. 
lece de una suerte de teleologismo que el concepto de Eigen-sinn evita, ya que la concepción de este último se vuelca en reconocer el significado sustantivo que las acciones adquieren para los individuos. Desde este punto de vista, y sin querer abundar en el tema del levantamiento de Romans, acciones como las descritas por Scott serían más un fin en sí mismo que un medio para alcanzar otro fin superior. El Eigen-sinn nos conduce a mantener la radical historicidad de las experiencias de los individuos y, por ello, lo vemos como una herramienta pertinente que desenmaraña las complejas y confusas dicotomías de resistencia-colaboración en las que a veces se embrolla la historiografía y que son poco útiles a mi juicio ${ }^{21}$. Así, el Eigen-sinn se puede definir como la creación de un espacio propio - de manera privilegiada en contextos dictatoriales - , la apropiación del medio y la dotación de significados subjetivos a las acciones. Este será el enfoque con el que se conciban las motivaciones de un ciudadano anónimo como Bonifacio García Duarte, intentando desentrañar desde su propia subjetividad cuál era su «espacio de experiencia y su horizonte de expectativa $\iota^{22} \mathrm{y}$, con ello, los motivos que le llevaron a escribir una dura carta de protesta al jefe de la Obra Sindical, José María Gutiérrez del Casti1lo, así como interpretar qué, cómo y por qué escribió de la forma que lo hizo.

\section{Educación y Descanso en tiempos de Solís}

En los meses de mayo y junio de 1959 los trabajadores españoles de los diversos sectores del país ultimaban los detalles de las vacaciones que habrían de disfrutar ese verano. Al mismo tiempo que Enrique Fuentes Quintana y el grupo de economistas a las órdenes del encargado del Plan de Estabilización, Laureano López Rodó, dilucidaban qué formulación le convenía más al plan ${ }^{23}$, Bonifacio García Duarte, su esposa y su hija de 14 meses buscaban cómo obtener un puesto de vacaciones que les permitiera disfrutar del verano. García Duarte era un trabajador metalúrgico asentado en el popular barrio madrileño de Palos de la Frontera. Además, estaba afiliado al Sindicato del Metal y tenía carné de miembro de la Obra Sindical de Educación y Descanso. Su militancia en Educación y Descanso, a la par que el escaso presupuesto de su familia (es más que probable que la esposa trabajase en casa, esto es, no tuviese remuneración), le impulsaron a solicitar, como hacían decenas de miles de trabajadores cada año, un puesto en las residencias de vacaciones de la Obra Sindical ${ }^{24}$.

${ }^{21}$ HERNÁNDEZ BURGOS, 2017.

22 KOSELLECK, 1993: 333-359.

${ }^{23}$ FUENTES QUINTANA, 1984: 25-40.

${ }^{24}$ Carta de Bonifacio García Duarte a José María Gutiérrez del Castillo, 28.7.1959, AGA, 006.005.01, caja 15145 . 
Educación y Descanso era una de las Obras Sindicales fundadas dentro de la Organización Sindical Española (OSE) en la inmediata postguerra. La OSE o «Sindicato Vertical» fue el modelo que adoptó el régimen para el control de la población y la «captación de las masas», copiando directamente algunos aspectos de la Italia fascista y la Alemania de $\mathrm{Hitler}^{25}$. En un principio, Educación y Descanso se llamaría "Alegría y Descanso», siendo alegría una traslación directa de la organización análoga nazi «La fuerza a través de la alegría» (Kraft durch Freude), a la cual pretendían emular tanto en sus medios como en sus objetivos ${ }^{26}$.

Cada verano, la demanda superaba en mucho a la oferta en las residencias de Educación y Descanso, por lo que había trabajadores que, pese a su militancia activa en la organización, habían esperado de manera infructuosa durante años unas vacaciones a precio reducido que nunca llegaban. No sabemos si García Duarte y su esposa habían solicitado y obtenido una plaza en las residencias en años anteriores, pero en 1959 tenían una razón más para lograr las ansiadas vacaciones. Su hija de 14 meses padecía una dolencia en el corazón y el médico le había recomendado la exposición al clima costero, ya que este podía ser beneficioso para su salud. García Duarte, en fecha tan tardía como el 24 de junio, había escrito una carta a la jefatura de la Obra Sindical, exponiendo los motivos que le impulsaban a solicitar o bien una plaza de alojamiento o bien, al menos, bonos de comida en una residencia cercana al mar.

El funcionamiento de Educación y Descanso había cambiado sustancialmente desde el nombramiento de José Solís como ministro secretario general del Movimiento en 1957. En la etapa de posguerra, la obra había adoptado un carácter netamente fascista con voluntad de control absoluto del tiempo libre de los individuos. Cuando la derrota de las potencias del Eje en la II Guerra Mundial se antojaba inevitable, el régimen relajó el carácter de la Obra Sindical, convirtiéndola en una organización al servicio del proyecto político de Franco y cortando las aspiraciones de algunos falangistas de llevar la fascistización del régimen hasta sus últimas consecuencias ${ }^{27}$. Pero el mayor cambio en la Obra Sindical se produjo años después, en unas circunstancias distintas que demandaban un funcionamiento más racionalizado y modernizado, para dar respuesta a la creciente demanda de turismo y vacaciones. Consciente de la derrota política de Falange frente al grupo de Carrero Blanco, Solís había pretendido impulsar una política social que aumentase la legitimidad y apreciación popular del Movimiento y del sindicato $^{28}$. Para ello, se había producido una renovación de personal, esto es, la vieja guardia de funcionarios, muy vinculados a los poderes locales tradicionales

${ }^{25}$ MOLINERO, 2005.

${ }^{26}$ LÓPEZ GALLEGOS, 2004: 215-236.

27 THOMAS, 2016.

${ }^{28}$ AMAYA, 2013: 15-24. 
en las ciudades, se había sustituido por una nueva generación, aunque estos cuadros habían sido seleccionados por Gutiérrez del Castillo, alguien que ya había ocupado cargos importantes en los cuarenta y que Solís recuperaba entonces nombrándole, con un espíritu renovado, jefe de la Obra ${ }^{29}$. Aun así, para los nuevos cuadros era fundamental una lealtad sin paliativos al general Franco, aunque Solís buscaba una racionalización de las Obras Sindicales que diera un mayor dinamismo a su funcionamiento y que intentase acabar con la lógica del privilegio, que en un ámbito como el de las vacaciones había sido la imperante. En 1959, se puso a prueba en Educación y Descanso el mecanismo del sorteo de puestos en las residencias de vacaciones precisamente para intentar acabar con la arbitrariedad y los intereses creados ${ }^{30}$. Bien es verdad que la lógica del privilegio nunca abandonó el Sindicato Vertical, pero con estos nuevos mecanismos se despersonalizaba la distribución de las plazas y, por lo tanto, se reducían las posibilidades de asignación personal de las mismas. Esto conllevaba, por otra parte, una mayor burocratización de la Obra Sindical, puesto que lo contrario a la lógica del privilegio arbitrario era una lógica con numerosas solicitudes y procesos administrativos que cumplimentar para optar a las vacaciones con el sindicato falangista.

Por ello, la carta de García Duarte del 24 de junio es a todas luces tardía, puesto que en esas fechas la práctica totalidad de las plazas de vacaciones habían sido ya distribuidas. Sin embargo, García Duarte obtuvo un éxito parcial en lo que demandaba. En la carta tenía preferencia un puesto completo de vacaciones en una residencia costera. Como segunda opción, que fue la que realmente se le concedió, mencionaba que, de no ser posible la primera, se le proporcionaran bonos de comida que sufragaran su estancia de forma parcial. La jefatura de Educación y Descanso accedió, por las especificidades del caso, a concederle los bonos para la Residencia «José Luis Narbona» de Torremolinos, en la Costa del Sol.

\section{Caridad y Justicial Social}

A lo largo de la investigación hemos visto cómo centenares de peticiones de puestos de vacaciones se rechazaban y si se puede decir que había algunas que tenían cierto éxito, éstas eran las que hacían referencia a la enfermedad de algún familiar, generalmente hijos o hijas, que necesitaba del aire de la montaña $\mathrm{o}$ - sobre todo- de la playa para reponer su salud ${ }^{31}$. El caso de Gar-

29 JIMÉNEZ, 2014: 249-250.

${ }^{30}$ Distribución de plazas en las Residencias de la Obra Sindical de Educación y Descanso, 1959, AGA, 006.005.01, caja 15144.

${ }^{31}$ Carta de Bonifacio García Duarte a José María Gutiérrez del Castillo, 28.7.1959, AGA, 006.005.01, caja 15145 . 
cía Duarte es uno de los pocos que adjunta un certificado médico que así lo demuestra. En muchos otros solamente se enuncia sin prueba empírica alguna. Por otro lado, si vemos este tipo de peticiones en conjunto, nos damos cuenta de que enfermedades muy dispares precisaban para su cura, según los médicos, del aire costero vacacional: desde dolencias de corazón hasta afecciones en la garganta y región rino-faringea ${ }^{32}$, pasando por todo tipo de enfermedades mentales e, incluso, casos en el que simplemente se habla de «enfermedad» en tono genérico. Así, por ejemplo, en 1959 se pedía, por parte del periodista Emilio Romero, una plaza para la familia de «un chico que está bastante fastidiado del corazón, y el médico le ha recomendado que salga con su hijo a ser posible a una playa, debido a la enfermedad del niño» ${ }^{33}$, sin adjuntar ningún tipo de documento acreditativo, solamente apelando a la comprensión y la buena voluntad del jefe nacional de Educación y Descanso - aunque también a la autoridad de Romero, como se hablará más adelante-.

Esto nos lleva a tres posibles escenarios no excluyentes que nos permiten entender un poco mejor de qué forma los ciudadanos intentaban, en una dictadura tan represiva como era el franquismo y en la que el privilegio de los más adeptos era moneda común, maximizar sus posibilidades de obtener unas merecidas vacaciones. La primera de ellas es que, efectivamente, todos los hijos de las familias que solicitaban un puesto de vacaciones en base a esto estuviesen en realidad enfermos y precisaran del clima costero. La segunda es que, estando enfermos, aunque dicha enfermedad no requiriese de un clima específico, intentasen sacar provecho de ello y argüir la enfermedad como argumento para un puesto de vacaciones. En este caso estaríamos ante una de las aplicaciones del eigen-sinn ${ }^{34}$ que, como se comentaba al inicio, hace referencia a cómo, hasta en contextos altamente represivos, el individuo es capaz de crearse un espacio propio, de maximizar sus posibilidades y, en definitiva, en este caso, de obtener algo que desea, las vacaciones, utilizando uno de los mecanismos que el Estado dispone para ello.

Un tercer y último escenario, también encuadrado en las acciones de eigensinn, sería el segundo llevado al extremo, esto es, que familias o particulares arguyeran enfermedad de un hijo o hija, en base a que la rumorología y también la práctica había demostrado que, de este modo, las posibilidades de obtener una habitación en las residencias de verano crecían de manera exponencial. Lo que nos induce a pensar de esta forma en este tercer caso es que muchas de las solicitudes que hablaban de hijos enfermos eran muy vagas en la descripción de la enfermedad en cuestión y no incluían certificado médico alguno. Un

${ }^{32}$ AGA, 006.005.01, caja 15145, 17.5.1959.

${ }_{33}$ Carta de Emilio Romero a José María Gutiérrez del Castillo, 18.6.1959, AGA, 006.005.01, caja 15145 .

${ }^{34}$ LUDTKE, 1993. LINDENBERGER, 1999. 
caso de este tipo es el de un padre de familia de Ceuta que había solicitado, sin éxito, durante dos años un puesto de vacaciones en la residencia de Sierra Nevada (Granada) y que aducía "yo tengo un pequeño con 6 años y el médico me ha recomendado que lo lleve a la Sierra, donde es factible que el cambio de clima le sentaría muy bien para su dolencia y este es el principal motivo por lo que molesto su atención $»^{35}$. Esta solicitud no incluía mayores referencias, por lo que es posible que fuera una familia de escasa capacidad económica intentando sacar ventaja, independientemente de si era real la enfermedad de su hijo o no, de una situación que sabían que podía funcionar.

Una evidencia que permite sostener que muchas de estas enfermedades no eran reales sino estrategias discursivas es que fue denunciado por médicos de la época. Así lo certificaba en un escrito un médico de prestigio en los años cincuenta:

... no siempre el veraneo del niño descansa sobre una causa que lo justifique; un programa de festejos que halaga a los padres es, en muchas ocasiones, el punto inicial de la partida; las alabanzas de un lugar determinado los anima a emprender la marcha sin saber si aquél es bueno o malo para la salud de los hijos; no siempre el médico es consultado; se resuelve a capricho, a la elección, y el veraneo no se basa sobre hechos científicos ${ }^{36}$.

La apelación a la supuesta enfermedad iba aderezada con alusiones a la caridad como razón última que debían seguir las autoridades. La caridad fue algo fundamental en el régimen franquista ${ }^{37}$, ya que, por su condición de católico, esta virtud ineludible en el credo religioso tenía que estar presente incluso en el ámbito político. No en vano en fechas señaladas, como las navidades, se producían indultos, redención de penas y exención de multas. De este modo, también el principio de caridad es visible en la distribución de las vacaciones de Educación y Descanso. A veces se incluía de forma explícita en las demandas de puestos de vacaciones, aludiendo a que su graciosa concesión no sería un

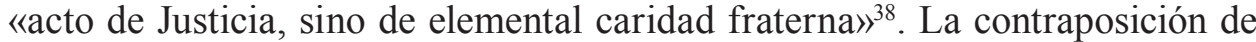
la justicia a la caridad se debe entender más bien como un ejercicio retórico, no como una negación de la legitimidad del régimen. Tanto más cuanto que los que demandaban puestos en Educación y Descanso eran en su mayoría gente, si no afín, al menos neutral y, en ningún caso, opositores al franquismo.

${ }^{35}$ Carta a Federico Olivencia Amor, 7.6.1965, AGA, 006.005.01, caja 15146.

${ }^{36}$ Garrido Lestache, Juan, El veraneo de un niño, visto por un médico: consejos para los padres y orientación para los maestros, Madrid, Editorial Magisterio Español, 1950: 20.

37 MINARDI, 2011: 117-133.

${ }^{38}$ Carta de Jaime Rubio a Federico Olivencia Amor. 25.4.1960, AGA, 006.005.01, caja 15146. 
La caridad era, no obstante, un territorio de disputa y las tensiones entre la Falange y la jerarquía católica española fueron evidentes desde el mismo origen del régimen ${ }^{39}$, ya que la Iglesia Católica pretendía arrogarse el monopolio de la misma. No por casualidad el mismo año de 1959 asistió a una de las tradicionales «Semana Social de España» organizada por la curia, bajo el título Caridad, beneficencia y asistencia social ${ }^{40}$.

En cualquier caso, la familia de García Duarte se benefició de una forma de actuar que, si bien no se calificaba como caritativa, tenía características muy similares. Esto respondía, a su vez, a la voluntad del Movimiento de Solís por ampliar su base social en la medida de lo posible, y ejercicios de caridad como el de García Duarte beneficiaban, sin duda, la imagen social de Falange, que para diversos sectores de la población aún era identificada con la violencia y la represión de la postguerra. Existían, incluso, formas menos comunes en las que se apelaba a la caridad para obtener un puesto de vacaciones, no por enfermedad de un familiar, sino por la muerte. Este es el caso de un miembro de Educación y Descanso de Ceuta, que pedía una plaza de vacaciones para él y su mujer en la Ciudad Sindical de Marbella, para que ésta superase la muerte de su madre en un ambiente relajado y alejado del estrés que le había provocado el deceso ${ }^{41}$. Recurrir a la caridad era, pues, una estrategia de los individuos para aumentar sus posibilidades de pasar unas vacaciones en condiciones favorables, por lo que no es de extrañar que muchas familias recurrieran a ello.

Por parte de Falange, el recurrir al ejercicio caritativo como algo no pautado, sino que depende en última instancia de la voluntad de la jerarquía de la Obra Sindical, nos muestra que los mecanismos estatales de distribución de vacaciones codificados por sorteo ni funcionaban ni eran tenidos en cuenta por los solicitantes de las mismas. El régimen de Franco en su segunda mitad buscó, a toda costa, una institucionalización que pasara por una codificación de los principios de funcionamiento del régimen, en definitiva, una burocratización hecha por administrativistas como los hombres de López Rodó ${ }^{42}$. En esa obsesión por codificar con respecto a los principios del derecho todos los aspectos de la sociedad, los mecanismos caritativos tenían un difícil encaje, debido a que eran un terreno que tenía más que ver con lo religioso y, por tanto, que se resistía a ser reducido a una serie de reglas fijas y pautadas. El ejercicio de la caridad como principio rector escapa, en buena medida, a una institucionalización estatal que, aunque proyecto derrotado, también fue uno de los objetivos del ministro secretario general del Movimiento José Solís ${ }^{43}$. De

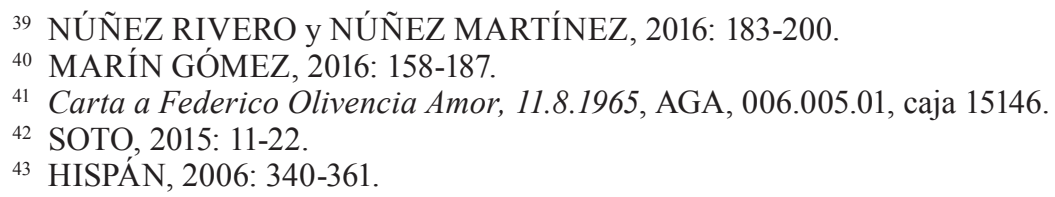


hecho algunos falangistas negaban la dimensión caritativa de la Obra Sindical, tal y como describe un veraneante que se quejaba a Gutiérrez del Castillo por el mal trato recibido por parte del jefe de una de las residencias, al que, según él, habría que enseñar «a tratar con la debida consideración a los residentes, que no van a una Institución de Caridad, sino a un lugar creado para ellos, que pagan, y en el que tienen derecho a toda clase de atenciones, como es precisamente el espíritu que anima a la Obra ${ }^{44}$.

En este caso se habla de «derecho», algo que conecta con el sentido de la justicia, más concretamente, la justicia social. Del mismo modo el caso principal que aquí tratamos, el de García Duarte, apunta en ese sentido puesto que denuncia situaciones de injusticia a fin de que Educación y Descanso «proceda a una justicia social bien encauzada para el verano que viene». Desconocemos la procedencia ideológico-política de García Duarte, pero parece clara su vinculación al Movimiento, así como que ha interiorizado el discurso de «justicia social» de Falange que, tras la llegada de Solís al ministerio, adquirió mayor vigor. La apelación a la «justicia social» o al «derecho» nos muestra un perfil diferente de cómo se establecía la relación entre los individuos y la Obra Sindical en lo que a las vacaciones se refiere. Aquí sí nos adentramos en un terreno más pautado y menos sujeto a la voluntad arbitraria que la caridad sugiere. Por otro lado, la dimensión no solamente de «derecho» sino de «derecho a toda clase de atenciones», aunque es ambigua pues no especifica a qué atenciones refiere, sí que nos conduce a evaluar la concepción de la experiencia vacacional en unos términos que conectan con el tipo de vacaciones europeas de los países liberales ${ }^{45}$. La carta no apela a una suerte de experiencia vacacional falangista de encuadramiento en una comunidad nacional con unos valores determinados, sino más bien a unas atenciones en un sentido amplio por las que, además, se ha pagado, lo cual refleja la dimensión de mercancía del turismo que ofrecía Educación y Descanso, que terminaron por no alejarlo demasiado de los valores burgueses a los que teóricamente se oponía.

Esta apelación al «derecho» o a la «justicia social» la encontramos en mayor número en los miembros de la Obra Sindical que en los ciudadanos, que apelaban más a la caridad como forma de obtener un puesto de vacaciones. No obstante, como nos muestran algunas de las fuentes, sería un error contraponer justicia social y caridad, ya que para algunos sujetos eran dos dimensiones entrelazadas y apelaban a las dos de forma conjunta para ampliar al máximo su argumentario de cara a la obtención del puesto de vacaciones. Es el caso de un ciudadano de Almansa, que encaja en los modelos de solicitud de vacaciones a través de enfermedad que describíamos más arriba. El individuo en cuestión

${ }^{44}$ Carta de Juan María Moya a José María Gutiérrez del Castillo, 1.9.1964, AGA, 006.005.01, caja 15149.

${ }^{45}$ TURNER y ASH, 1999. 
se ve impulsado a escribir a Educación y Descanso en base a «una conmoción cerebral gravísima» que se une a otros factores y culmina en «la trágica incapacidad que padezco, junto a unos medios económicos escasos y el ansia natural y muy humana de cambiar de ambiente una temporada». Así, escribe para

Solicitar de toda la magnanimidad caritativa de su corazón, armonizable con su recto y humano sentido de la más pura justicia social. expresión viva del RÉGIMEN, ser incluido, junto con mis esposa e hija, ésta de cuatro años de edad, en uno de los turnos de verano de cualquier residencia de la Obra Sindical de Educación y Descanso ${ }^{46}$.

Como vemos, aquí se superpone el discurso de la caridad con el de la justicia social, por lo que no resulta sencillo comprender de qué forma se conjugaban ambos en aquellos que, apelando a dichos conceptos, se dirigían por carta a la jefatura de Educación y Descanso. En cualquier caso, tal y como está formulado, la concepción de la justicia social alberga aquí una dimensión que tiene más que ver con lo caritativo y que es subsidiaria a ello. Del mismo modo, en la documentación analizada la dimensión caritativa alberga un peso específico mayor, lo que da a entender que no percibían las instituciones de una forma garantista, esto es, con unas reglas fijas a las que poder apelar para adquirir los servicios que ofrecían. La caridad como forma para obtener lo que se deseaba era acompañada por otras virtudes de raíz cristiana como la piedad, — que tienen un origen paralelo al de la caridad y están presentes en el pensamiento español desde, al menos, el renacentista Luis Vives - ${ }^{47}$. Así lo muestra el caso de un trabajador ferroviario que, tras varios años de infructuosas solicitudes por los cauces legales de una plaza de vacaciones se quejaba amargamente en una carta a la jefatura de la Obra: «¿Es que en 13 años no ha habido una persona piadosa que se haya parado a pensar en el atropello que esto supone? $\wedge^{48}$.

\section{La experiencia de vacaciones. Privilegios, decepción y Críticas}

Bonifacio García Duarte, su mujer y su hija llegaron a la residencia de Torremolinos un día tan significado como el 18 de julio. Tras entregar el volante justificativo de los bonos al jefe de la residencia, encontraron un alojamiento no muy alejado de la misma. El haber obtenido bonos de comida, aunque no alojamiento, permitía que pasasen buena parte del día en la residencia. Aunque el lugar de hospedaje de la familia estaba situado a

${ }^{46}$ Carta de Antonio Antúnez a José María Gutiérrez del Castillo, 16.6.1959, AGA, 006.005.01, caja 15144.

47 GEREMEK, 1989: 123-154.

48 Carta de Fidel Agustín a Federico Olivencia, 9.7.1960, AGA, 006.005.01, caja 15144. 
... dos o tres kilómetros (...) aquel ajetreo de ir, venir, preparar las comidas de la niña, buscar alimentos para ella, etc. era demasiado, saliendo con ello perjudicada nuestra hija, que en realidad por ella hacíamos aquel gasto y no se la atendía convenientemente ${ }^{49}$.

Esta situación causó profundo descontento en el matrimonio que, incluso, comenzó a plantearse, el día después de haber llegado a sus vacaciones, el volverse antes de tiempo y renunciar así a lo que Educación y Descanso les había concedido. El sentimiento de enfado y «desesperación» se vio agravado la mañana del 19 de julio. Estando en las dependencias de la residencia junto con otras familias hizo aparición un «flamante Renault $4 x 4$ », un coche muy poco habitual por su lujo, máxime si tenemos en cuenta que en 1959 el coche en propiedad era aún poco común y, por lo tanto, un marcador de estatus social y económico en la sociedad española. La familia del Renault $4 \times 4$ utilizó «el jardín de la residencia como garaje» ante los comentarios de las familias que pasaban por allí, que, tal y como lo enuncia García Duarte, suponemos que fueron de desaprobación y descontento ${ }^{50}$.

Pero todo fue a peor cuando este y su familia se enteraron de que los del $4 \times 4$ disfrutaban de estancia completa: «Este incidente me movió a dirigirme al jefe de la Residencia en demanda de una habitación, no sin antes exponerle nuestro caso y nuestra delicada situación, de la que se hizo cargo, pero contestándome que sintiéndolo mucho, no disponía de ninguna habitación». García Duarte intentó usar el caso de «los señores del coche» para conseguir lo que ya con anterioridad deseaban, esto es, una habitación en la residencia que les evitara las idas y venidas varias veces al día. El jefe de la Residencia empatizó con su caso, además de quejarse del overbooking de las habitaciones, pues había 88 personas cuando la capacidad era de apenas 75. Coincidió con Bonifacio en que tenía «toda la razón para estar indignado, pero él tenía la misión de dar alojamiento a todos los que fueran con los bonos de estancia debidamente diligenciados y que, no obstante, daría parte a la Delegación Provincial de ello» ${ }^{51}$.

Estos partes a la Delegación Provincial fueron muy habituales, además, por casos similares en los que familias en apariencia pudientes disfrutaban de unas residencias que, en teoría, estaban pensadas para los trabajadores. Los motivos eran similares y aludían a lo más obvio, la posesión de un coche. Así reportaba por ejemplo el jefe de la Residencia de Educación y Descanso de Aguadulce (Almería) en 1961: «Estamos hartos de ver a un elevado porcentaje de residentes que acuden a éstas con coche propio, cuando desgraciadamente hoy por hoy

${ }^{49}$ Carta de Fidel Agustín a Federico Olivencia, 9.7.1960, AGA, 006.005.01, caja 15144.

${ }^{50}$ Carta de Bonifacio García Duarte a José María Gutiérrez del Castillo, 28.7.1959, AGA, 006.005.01, caja 15145.

${ }_{51}$ Carta de Bonifacio García Duarte a José María Gutiérrez del Castillo, 28.7.1959, AGA, 006.005.01, caja 15145. 
este vehículo no se encuentra al alcance de la mayoría de los productores $\rangle^{52}$. Este director aducía que «gran parte de los residentes pueden costearse su veraneo en otros lugares, por lo que debe velarse para que vayan los económicamente débiles», con lo cual apuntaba a la mala distribución de plazas que, a pesar de haberse introducido el mecanismo de sorteo dos años antes, seguía favoreciendo a familias que no lo necesitaban. Iba, incluso, más allá, hasta cuestionar el fundamento mismo de las residencias y enunciar que «quizás ya no estemos tan seguros de que esa función político-social se cumpla en toda su pureza $\aleph^{53}$. La función político-social era fundamental en el organigrama del Movimiento y, en este caso, de Educación y Descanso. Por un lado, para la promoción de unos valores políticos acordes al régimen de Franco y, por otro, para la cobertura social del derecho al descanso y las vacaciones que el franquismo recogía desde el Fuero del Trabajo de 1938. El caso de Aguadulce no es el único de un jefe de Residencia que muestra indignación por la extracción social de los vacacionistas. Así, el jefe de una Residencia de Huesca, escribía al Jefe Nacional de Educación y Descanso para comunicarle:

... me permito hacer observar en este informe que, al correr los turnos en este año, he podido percatarme de que la mayoría de los residentes, por no decir la totalidad, son productores que gozan de una posición económica desahogada, cosas que queda bien patente en los signos externos de los mismos, cuando no en el uso de coche propio ${ }^{54}$.

De la misma forma, el jefe de una Residencia en Albacete reportaba:

Esta temporada hemos tenido un porcentaje extraordinario de residentes con coche y (...) hubo un turno que había frente a la instalación 11 coches aparcados, lo que dio lugar a veces a que los extranjeros que pasaban creyeran era un Hotel o Parador de Turismo, e intentaban pernoctar o comer en la Residencia. (...) esto creaba una atmósfera en los dos o tres primeros días de crítica por parte de los que no traían vehículo al ver que la instalación era disfrutada por personas pudientes ${ }^{55}$.

Como García Duarte, la crítica no era tanto a la situación en la que se encontraban algunas residencias, con comidas de baja calidad, habitaciones sucias o pocas actividades de ocio, cuanto a que se violara el principio de justicia social del que había hecho gala el Movimiento y la Obra Sindical de Educación y Descanso. Además, de cara al exterior, como aludía el informe de Albacete, daba a la residencia un aspecto de hotel o de alojamiento turístico convencional que

${ }^{52}$ Residencia de Aguadulce (Almería), 9.9.1961, AGA, 006.005.01, caja 14282.

${ }_{53}$ Residencia de Aguadulce (Almería), 9.9.1961, AGA, 006.005.01, caja 14282.

${ }^{54}$ Carta a José María Gutiérrez del Castillo. 3.8.1961, AGA, 006.005.01, caja 14282

${ }^{55}$ Residencia de Albacete. 8.9.1961, AGA, 006.005.01, caja 14282. 
atraía a foráneos, con lo cual se rompía con la voluntad utópica de Falange por crear unas vacaciones que, por un lado, rompiesen con las vacaciones proletarias de lucha de clases en favor de la construcción de una determinada comunidad nacional, y, por otro, se alejasen del descanso burgués capitalista reservado a una minoría que, además, propiciaba un ocio embrutecedor y nihilista. En los años sesenta ya había muy poco espacio para la utopía del fascismo de entreguerras, pero los funcionarios de Falange aún albergaban algún tipo de esperanza que se daba de bruces con la realidad, como escribe el jefe de la Ciudad Residencial de Tarragona con

\begin{abstract}
... la imposibilidad de hacer nada importante que haga que la Residencia no parezca un hotel de más o menos categoría en el aspecto de las relaciones sociales. Por desgracia, la supresión de las consignaciones para esta necesidad y la falta de unos locales para estas atenciones es consecuencia de que entre los residentes no nazcan esas relaciones tan interesantes para que hombres de distintas regiones se conozcan para formar nuestra ansiada unidad ${ }^{56}$.
\end{abstract}

Estas palabras del responsable de la Ciudad Residencial de Tarragona son relevantes en tanto que ésta era una de las tres ciudades sindicales, junto con Perlora y Marbella, que disponían de más recursos que la mayoría de las otras $\mathrm{y}$, por tanto, las posibilidades de organizar actividades eran superiores ${ }^{57}$.

En las palabras que se han citado alude a lo laxo de las relaciones sociales por la supresión de las consignaciones, esto es, que en las vacaciones se producían unos contactos que poco o nada tenían que ver con el encuadramiento falangista y con los valores que estos pretendían promover. También indica la dificultad que los miembros de Educación y Descanso tenían para controlar el comportamiento y las actividades de los veraneantes, y de ahí que las aspiraciones utópicas de instaurar un ocio falangista de valores castrenses y nacionalistas fuera algo que funcionaba más en la teoría que en la práctica.

La «ansiada unidad» a la que refieren las palabras del jefe de la ciudad sindical, responde al tipo de nacionalismo falangista, de tinte organicista y de proyección del futuro de la nación, como «unidad de destino en lo universal», tal y como rezaba el lema de trazas orteguianas acuñado por José Antonio Primo de Rivera ${ }^{58}$. Una ansiada unidad como proyecto utópico que era mucho menos apreciada que otro tipo de valores de esparcimiento y ocio hoteleros. Como denunciaba el delegado provincial de Educación y Descanso en Granada al Jefe Nacional Gutiérrez del Castillo:

56 Informe del Jefe de la Ciudad Residencia de Tarragona. 7.9.1961, AGA, 006.005.01, caja 14282.

57 CARCELÉN, 2017: 151-154.

58 SAZ, 2003: 11-23.

Hispania, 2021, vol. LXXXI, n. ${ }^{\circ}$ 269, septiembre-diciembre, págs. 767-795, ISSN: 0018-2141, e-ISSN: 1988-8368 https://doi.org/10.3989/hispania.2021.020 
Creo que en algunas residencias, los jefes deben preocuparse en fomentar algo el espíritu de hermandad y camaradería de los productores que a ellas concurren (...) algunos se limitan a parecerse a directores de hoteles, que se refugian en sus despachos, no conviviendo con los productores produciéndose entre las varias familias esa frialdad más propia de los establecimientos hoteleros y que hace no se encuentren los afiliados como en su propia casa ${ }^{59}$.

Los funcionarios de Educación y Descanso demandaban una mayor implicación por parte de todos los miembros de la organización, que redundase en más actividades políticas destinadas a elevar la formación de los veraneantes, aunque este tipo de actividades no solían ser bien recibidas y, por lo tanto, tenían una difícil aplicación práctica ${ }^{60}$.

Las vacaciones, el período del año que con más ansia y deseo esperaban los trabajadores españoles, fueron un episodio frustrante para la familia de García Duarte. A nivel de descanso y ocio el disfrute había sido casi inexistente y, a nivel terapéutico, el panorama era aún más desolador puesto que la hija del matrimonio «no pudo tomar los baños de sol como el médico la (sic) indicó» ${ }^{61}$. Las quejas principales de García Duarte se referían a la dimensión terapéutica que sus vacaciones debieran haber tenido más que a cuestiones de ocio y descanso. Él llegó a culparse respecto al asunto de su hija «por no tener dinero suficiente para veranear», pero, al mismo tiempo, repartía la culpa y señalaba que quizá la plaza que «le correspondía humanamente, la ocupó un señor que bien puede pagar "residencia" en cualquier hotel de España y no en una residencia de "productores", que al fin y al cabo es a quienes corresponden y para quien se han llevado a cabo las mismas ${ }^{62}$. Esta queja iba dirigida en forma de carta al Jefe Nacional de Educación y Descanso, Gutiérrez del Castillo y, por encontrase ausente, fue recibida por el secretario general de la organización, Federico Olivencia Amor. La manera en que está escrita la carta, tanto por la forma como por el contenido, nos indica de qué modo se relacionaba García Duarte con una de las facciones del régimen como era la Obra Sindical y el grado de legitimidad que le concedía. La carta acaba con un significativo «creyendo haber cumplido con mi deber ${ }^{63}$, con el que García Duarte muestra su grado de compromiso con el régimen.

59 Carta del Delegado Provincial de Granada de la Obra Sindical de Educación y Descanso a José María Gutiérrez del Castillo. 1.9.1961, AGA, 006.005.01, caja 14282.

${ }^{60}$ DÍAZ BELLO, 1999: 241-253.

${ }^{61}$ Carta del Delegado Provincial de Granada de la Obra Sindical de Educación y Descanso a José María Gutiérrez del Castillo. 1.9.1961, AGA, 006.005.01, caja 14282.

${ }^{62}$ Carta del Delegado Provincial de Granada de la Obra Sindical de Educación y Descanso a José María Gutiérrez del Castillo. 1.9.1961, AGA, 006.005.01, caja 14282.

${ }^{63}$ Carta del Delegado Provincial de Granada de la Obra Sindical de Educación y Descanso a José María Gutiérrez del Castillo. 1.9.1961, AGA, 006.005.01, caja 14282. 
A diferencia de otros regímenes dictatoriales de la Europa contemporánea como los sistemas socialistas, en especial la República Democrática Alemana ${ }^{64}$, este tipo de cartas directas a un alto mando no eran muy habituales. Esta clase de misivas que, por un lado, denunciaban una injusticia o situación de indefensión personal y, por otro, tenían un, más o menos sincero, compromiso con el sistema y con su mejora no tuvieron un cauce legal directo promocionado abiertamente por las autoridades franquistas. A diferencia del sistema de Eingaben (peticiones) de la República Democrática Alemana, que instauraba una vía de contacto clara que se atendía con diligencia y con ciertas posibilidades de éxito ${ }^{65}$, en el franquismo, por la documentación que hemos consultado, este tipo de cartas se encuentran dispersas en el marasmo de los archivos y hay que realizar un auténtico tour de force para encontrarlas, recopilarlas y analizar qué nos pueden decir, en este caso sobre el funcionamiento de la política de vacaciones del Movimiento.

La escasez de este tipo de fuentes y la no sistematicidad de su recopilación y respuesta, nos hace que pensar que un tipo de carta como la de García Duarte es probable que estuviera escrita por alguien cuyo vínculo con el sistema le impulsaba, por una suerte de responsabilidad interna, a elevar una queja al jefe de la Obra Sindical. No hemos de perder de vista, por otro lado, que el fin de la carta, si bien secundariamente se apunta a una mejora general de la justicia social, tiene como objeto un caso de agravio personal que busca reparación o compensación, por lo que puede ser tomada por una carta de un particular que busca resarcirse de una injusticia. Al mismo tiempo, es relevante porque con la redacción y envío de la misma existe una cierta esperanza de ser escuchado y atendido. En la República Democrática Alemana, las quejas mediante el sistema de Eingaben acababan siendo un factor de legitimación y estabilización del régimen, puesto que el ciudadano percibía que había unos cauces legales que atendían problemas particulares. En el franquismo no era así, pero cartas como la de García Duarte muestran que se concedía cierta legitimidad al sistema, puesto que se esperaba obtener algo de él.

Bonifacio García Duarte situaba su queja con respecto al fundamento de origen de las residencias de verano. Como veíamos más arriba que hacían algunos funcionarios de Educación y Descanso, es ahora un particular el que se pregunta: «¿Las residencias de EyD son sola y exclusivamente para productores o también lo son y tienen cabida en ellas personas que disponen de coches y quizá de alguna que otra propiedad industrial o territorial, que ya dejan de ser

${ }^{64}$ NIETHAMMER, WIERLING y PLATO, 1991.

${ }^{65}$ Eingaben der Bürger - eine Form der Verwirklichung des Grundrechtes auf Mitbestimmung und Mitgestaltung: Materialen der 18. Sitzung des Staatsrates der DDR am 20, November 1969, THULB. 
productores porque no pagan la cuota sindical $\left.?^{66}\right)$. Aquí se mezcla el discurso de la justicia social con el corporativo, ya que no solo denuncia a las personas de alto nivel adquisitivo, sino también el acceso a las residencias de aquellos que no pagan una cuota sindical. Respecto a lo primero, como hemos apuntado más arriba, había muchos miembros de la Obra Sindical de acuerdo. En cuanto a la afiliación sindical, en vista de la política expansiva de Solís y de búsqueda de una base social lo más amplia posible, Educación y Descanso comenzó a plantearse no exigir la membresía en la Obra para acceder a muchos de sus servicios $^{67}$. El objetivo de esto era expandir socialmente a la organización, pero lo cierto es que redundaba, como se ha visto, en que empresarios sin filiación sindical y de alto poder adquisitivo accedieran a unos servicios en teoría destinados a las capas más desfavorecidas de la población. La respuesta que respecto a esta cuestión daba Olivencia Amor a García Duarte decía lo siguiente: «No debemos cerrar nuestras puertas a quienes viven de su trabajo pero que por imperativos de Ley no están obligados al encuadramiento sindical ${ }^{68}$.

Pero las quejas de García Duarte respecto a las vacaciones no demandaban un privilegio por ser miembro del sindicado de la obra. Más bien al contrario, el grueso de sus reivindicaciones se dirigía a que las propias normas del régimen se cumpliesen «a rajatabla». Esto incide en lo que se apuntaba sobre la legitimidad que este concedía al sistema. Una legitimidad cuyo alcance es difícil de calibrar, pero que es tal en tanto que, al menos, reconoce la existencia de unas normas impuestas por el sistema a la vez que exige su cumplimiento. García Duarte expone:

Según una circular que me mostraron en el Sindicato Provincial del Metal, los que disfrutaron de residencia el pasado año, éste no tenía derecho ni siquiera a solicitarlo, pues bien, los residentes de Torremolinos, en su mayor parte, habían estado el año pasado, el anterior y el otro, si no en la misma en distintas y en las mejores emplazadas (...). Según dicha circular, la Residencia de Torremolinos, es sola y exclusivamente para matrimonios con un solo hijo, pues, los había sin ninguno, con uno, con dos y con tres ${ }^{69}$.

Aquí la crítica se torna más abierta, puesto que muestra los privilegios de los que algunos disfrutaban dentro del régimen, que se manifestaban en la asis-

${ }^{66}$ Carta de Bonifacio García Duarte a José María Gutiérrez del Castillo, 28.7.1959, AGA, 006.005.01, caja 15145 .

${ }^{67}$ Carta del jefe del departamento de Afiliación al Jefe Nacional, 24.11.1959, AGA, 006.005.01, caja 15145 .

${ }^{68}$ Carta de Federico Olivencia Amor a Bonifacio García Duarte, 26.8.1959, AGA, 006.005 .01 , caja 15145 .

${ }^{69}$ Carta de Bonifacio García Duarte a José María Gutiérrez del Castillo, 28.7.1959, AGA, 006.005.01, caja 15145 .

Hispania, 2021, vol. LXXXI, n. ${ }^{\circ}$ 269, septiembre-diciembre, págs. 767-795, ISSN: 0018-2141, e-ISSN: 1988-8368 https://doi.org/10.3989/hispania.2021.020 
tencia a residencias de vacaciones, sin paso previo por el sorteo de Educación y Descanso, y los diversos mecanismos legales que el régimen tenía.

Aquí destaca la figura de «el recomendado», una figura de privilegio que se mantuvo desde el inicio al final del régimen y que mostraba las desigualdades imperantes en función de la mayor o menor cercanía al poder que se tuviese. Un recomendado era normalmente alguien que por cercanía de primer, segundo o tercer grado tenía un acceso a alguna figura de poder, la cual intercedía por él ante según que instancias para concederle algún beneficio que, sin esa ayuda, hubiera sido o bien costoso en tiempo y en dinero o bien imposible de obtener. García Duarte lo expone abiertamente en su carta a través de una pregunta retórica: «¿No hay ninguna forma para poder llevar estas normas a rajatabla y que no haya recomendados? $\gg^{70}$. Es difícil saber el alcance real del «recomendado» en el franquismo, cómo se manifestó en cada momento y de qué manera variaba de un sector a otro. En lo que a Educación y Descanso se refiere, Gutiérrez del Castillo, Olivencia y demás miembros de la Obra Sindical se propusieron reducirlo al mínimo, de nuevo como forma de mejorar la imagen social de la Falange. Como muestra el caso de García Duarte, es evidente que no lo consiguieron y el «recomendado» siguió disfrutando de sus privilegios en lo que a puestos en las residencias de verano se refiere.

Sí que podemos destacar, sin embargo, algunas negaciones de privilegios de vacaciones a recomendados de figuras muy señeras del régimen y de Falange en particular. Es el caso de Raimundo Fernández Cuesta, antiguo ministro secretario general del Movimiento y un «camisa vieja» histórico de gran prestigio en las filas de Falange. Uno de los casos en los que se negó ayuda a Fernández Cuesta fue en 1963, al solicitar este una plaza en Tarragona o en Marbella, _al ser dos de las ciudades sindicales eran dos de los destinos más demandadospara una persona de su recomendación ${ }^{71}$, a lo que Gutiérrez del Castillo, desde Educación y Descanso, respondió que si la persona en cuestión quería una plaza de vacaciones habría de solicitarla por el grupo de empresa que le correspondía, aunque acababa confesándole su «pesar por no poder hacer nada de lo que me pides» $\rangle^{72}$. También es el caso, en 1965, del ministro de Marina en cargo, el general Pedro Nieto Antúnez, que pidió plaza en una residencia de vacaciones para un trabajador a su servicio que no la había obtenido por los cauces habituales, obteniendo también un no por respuesta ${ }^{73}$. Los recomendados que

${ }^{70}$ Carta de Bonifacio García Duarte a José María Gutiérrez del Castillo, 28.7.1959, AGA, 006.005.01, caja 15145.

${ }^{71}$ Carta de Raimundo Fernández Cuesta a José María Gutiérrez del Castillo, 14.6.1963, AGA, 006.005.01, caja 15147.

${ }^{72}$ Carta de José María Gutiérrez del Castillo a Raimundo Fernández Cuesta, 19.6.1963, AGA, 006.005.01, caja 15147.

${ }^{73}$ Carta de Pedro Nieto Antúnez a Federico Olivencia Amor, 23.6.1965, AGA, 006.005.01, caja 15147.

Hispania, 2021, vol. LXXXI, n. ${ }^{\circ}$ 269, septiembre-diciembre, págs. 767-795, ISSN: 0018-2141, e-ISSN: 1988-8368 https://doi.org/10.3989/hispania.2021.020 
fueron rechazados por la dirección central de Educación y Descanso son una amplia nómina, desde los mencionados hasta cargos menores como el jefe del Sindicato Español Universitario (SEU) Rodolfo Martín Villa, y pasando por cargos locales y regionales cuyos «recomendados» rara vez se beneficiaron del privilegio de pasar las vacaciones en una de las residencias de la Obra Sindical.

A pesar de que el organismo central en Madrid de Educación y Descanso negaba sistemáticamente un porcentaje considerable de peticiones de vacaciones para los «recomendados» de los cargos del régimen, ésta no era la única instancia que éstos tenían a su disposición para colocar a sus allegados en las residencias de la Obra Sindical. En la mayoría de las ocasiones, Gutiérrez del Castillo y Olivencia negaban la concesión directa del puesto de vacaciones y, en cualquier caso, aducían que, si existía alguna posibilidad, esta debía ser estudiada por organismos de provincias. Es el caso de la respuesta de Gutiérrez del Castillo al presidente del Sindicato Nacional de la Vid, José María Monteagudo, que demandaba vacaciones para una familia en la Ciudad Residencial de Tarragona: «Carezco de cupo para ello ya que las renuncias que pueden venir de provincias son estudiadas por una Junta Central $\gg^{74}$. Es probable que estas Juntas Centrales, junto con otros organismos de provincias, fueran lugares en los que prosperasen los recomendados de las figuras del régimen y perpetuaran a nivel local el clima de privilegio característico de la dictadura, ocupando puestos en las residencias que no les correspondían, tal y como denunciaba en su carta García Duarte.

El control por parte de Educación y Descanso de la administración local, donde el privilegio vacacional del «recomendado» proliferaba, en la práctica era limitado. La política del sorteo en provincias era en no pocas ocasiones adulterada, como denuncia Teresa B.V, una funcionaria de tipo bajo - lo sabemos por su sueldo - de la Delegación Nacional de Sindicatos. El asunto ocurrió en Logroño en 1960, donde se sorteaban plaza para la residencia de Caparica, en Portugal:

... solo meten a sorteo las que quieren no las que existen, ya que he sido informada por fuente verídica que la única plaza otorgada a Logroño no ha salido en sorteo puesto que el interesado ya sabía antes del sorteo que tenía segura la plaza. (...) ¡Cómo es el azar de la vida! Habiendo productores con ingresos inferiores a 3000 ptas (sic) Mensuales la suerte ha ido a parar al único que había con sueldo reconocido por más de 8000 . ¿No le parece esto un poco anormal? ${ }^{75}$

Aquí señala la anormalidad del sistema, la situación de privilegio de algunos respecto a otros que, en este caso, se materializaba en que el beneficiario

${ }^{74}$ Carta de José María Gutiérrez del Castillo a José María Monteagudo, 15.6.1963, AGA, 006.005.01, caja 15147.

${ }^{75}$ AGA, 006.005.01, caja 15144, 14.5.1960. 
de la plaza era un jefe del Departamento del Instituto Nacional de Previsión. La autora de la queja utilizaba este ejemplo de la anormalidad de la distribución no solo como denuncia sino como medio para obtener ella misma una plaza en la residencia portuguesa y, así, apelaba a una cierta justicia social aclamada por el régimen, al no entender que, frente a su sueldo de 3.000 pesetas, veranearan «en residencias mis Jefes de Departamento con sueldo de 8 y 10 mil ptas.» Además de esta suerte de «rendición de cuentas» a la que Teresa B.V. fiaba su carta, concluía apelando al principio de justicia divina, que en la práctica y como mencionábamos más arriba es una plasmación de la demanda del principio de caridad cristiana: «Soy poca cosa para ser tenida en cuenta, pero qué vamos a hacer, Dios es justo y proveerá $)^{76}$.

Esta estrategia argumental para obtener un puesto de vacaciones, que no dio resultado, es una fuente clave para conocer las irregularidades de distribución. Desde la jefatura nacional de la obra se preguntó a los responsables logroñeses por el particular, a lo que ellos justificaron que la plaza «se ha concedido de manera normal y por nuestra parte no vemos anomalía alguna que haya sido beneficiario un Jefe de Negociado del Instituto Nacional de Previsión $\rangle^{77}$. La Jefatura Nacional, al menos en este caso y en otros similares que se han consultado, no emprendía acciones más allá, revelándose así su inacción ante lo que acontecía en las delegaciones provinciales, aunque por las burdas justificaciones que se han reproducido, a buen seguro eran plenamente conscientes de los privilegios vacacionales de algunos sectores.

No obstante, las lógicas locales de privilegio deberían ser estudiadas en cada caso concreto viendo a qué intereses respondían, porque es bien cierto que, a la vez que desde la jefatura central de la Obra Sindical se rechazaban muchas de estas peticiones, se aceptaron también algunas otras. El cariz de las que se aceptaban por parte de Olivencia y Del Castillo, en función de la documentación analizada, repetía en la mayoría de las ocasiones un patrón determinado. Así, por ejemplo, las — constantes - peticiones para recomendados del periodista Emilio Romero eran normalmente aceptadas. Emilio Romero era el director del diario del Movimiento «Pueblo», un periódico que se había caracterizado por defender la línea del falangismo opuesto a los tecnócratas del Opus Dei, incidiendo en su vertiente social ${ }^{78}$ y destacando sobremanera la labor de la Obra Sindical de Educación y Descanso. Con lo cual, Romero era un activo fundamental para dar voz a los logros de la Obra Sindical y, por lo tanto, redundaba en beneficio de la misma. Contrariamente a Raimundo Fernández Cuesta, que era una figura querida y respetada pero que no tenía nada que aportar de forma fehaciente a Educación y Descanso, la labor de Emilio

${ }^{76}$ AGA, 006.005.01, caja 15144, 14.5.1960.

77 Asesor Nacional de Obras Sindicales, 15.7.1960, AGA, 006.005.01, caja 15144.

${ }^{78}$ MUÑOZ, 2013: 343-365. 
Romero era necesaria y, por lo tanto, era, de algún modo, recompensada concediendo puestos de vacaciones a quien Romero recomendaba. Así, por ejemplo, en 1963 Romero pidió un puesto en la Ciudad Residencial de Tarragona para una familia de su recomendación ${ }^{79}$ que fue concedido por Gutiérrez del Castillo $^{80}$.

Romero era consciente de su posición necesario para Educación y Descanso, y eso le permitía hacer uso del recurso del recomendado varias veces, incluso, en el mismo verano, y destacaba su disposición favorable a Educación y Descanso «como una prueba más de buena voluntad de este director de periódico a su buen amigo José María Gutiérrez del Castillo» ${ }^{81}$. No obstante, a veces, sobre todo aún a finales de los cincuenta cuando el diario Pueblo todavía no hacía campaña abierta en favor de Educación y Descanso, también se rechazaba a sus recomendados ${ }^{82}$.

Emilio Romero no era el único que tenía algo que ofrecer a Educación y Descanso que llevase a Olivencia y Gutiérrez del Castillo a aceptar la petición de vacaciones. También se dio el caso con Alejandro Rodríguez de Valcárcel, director de Asuntos Sociales en el Instituto Nacional de Industria, porque él podía concederles partidas presupuestarias más elevadas para llevar a cabo acciones como la instalación de bungalows en la Ciudad Sindical de Marbella. Como confiesa Gutiérrez del Castillo a Pedro Lamata, secretario general de la Organización Sindical, esto era algo que no podía llevarse a cabo sin la ayuda de Rodríguez de Valcárcel ${ }^{83}$. De esta forma, podemos intuir que la concesión del privilegio al recomendado no se debió a un mecanismo exclusivamente endogámico y corporativo por el que los vencedores de la Guerra Civil se concedían regalías mutuas, sino que Educación y Descanso buscaba, en la línea marcado por Solís, maximizar su operatividad y radio de acción y, para ello, era necesario conceder ciertos privilegios a aquellos, como Emilio Romero o Alejandro Rodríguez de Valcárcel, que podían devolverle con creces prestaciones para mejorar el servicio de la Obra Sindical, ya que una de sus mayores preocupaciones tenía que ver con el presupuesto del que dispusieran ${ }^{84}$.

Bonifacio García Duarte era ajeno al funcionamiento interno de la Obra Sindical, y su caso nos sirve para ilustrar como un ciudadano corriente, sin

79 Carta de Emilio Romero a José María Gutiérrez del Castillo, 15.6.1963, AGA, 006.005.01, caja 15147.

${ }^{80}$ Carta de José María Gutiérrez del Castillo a Emilio Romero, 22.6.1963, AGA, 006.005.01, caja 15147.

${ }^{81}$ Carta de Emilio Romero a José María Gutiérrez del Castillo, 1.8.1963, AGA, 006.005.01, caja 15147.

82 AMILIVIA, 2005: 71-103.

${ }^{83}$ Carta de José María Gutiérrez del Castillo a Pedro Lamata Megías, 13.7.1963, AGA, 006.005.01, caja 15147.

${ }^{84}$ Circular interna. 8.1.1964, AGA, 006.005.01, caja 15716. 
cargo administrativo alguno, veía los privilegios de los recomendados de aquellos con posibilidades económicas que ocupaban puestos que no debían corresponderles. Así cerraba su carta de denuncia:

Todo cuento (sic) le indico a Usted puede tomarlo como denuncia o como simple comentario, pero en el bien entendido, deseando que todas estas asperezas puedan irse limando y que, si las Residencias de EyD son para productores, que lo sean, pero únicamente para ellos y eliminar con ello estos errores, incomprendidos por los productores a los que se les deniegan plazas, (...) sean ellos los que tienen que dejar paso a señores, que además de no pagar cuota sindical, por lo que no corresponde a la Obra, tenga un carnet de afiliado mal concedido ${ }^{85}$.

En cualquier caso, la crítica, aunque explícita, no puede tomarse por un caso de disidencia u oposición al régimen, pero sí para ilustrar cómo los teóricos partidarios del régimen, como es más que probable que fuera García Duarte, experimentaron sus vacaciones en primera persona. En este caso, de una manera bastante decepcionante que hizo que su confianza en el sistema mermase.

\section{Conclusiones}

El caso García Duarte refleja cómo un ciudadano, que a priori se identificaba con el régimen, podía ejercer la crítica de formas que iban desde aspectos concretos a una velada puesta en cuestión de algunos de sus fundamentos más básicos. Esto muestra como la lealtad al sistema no era inamovible sino más bien volátil y dependía, en última instancia, de la práctica y de la satisfacción de las necesidades de la población. Así, los casos de quejas «desde abajo» y también las críticas de los propios funcionarios falangistas muestran un escenario dinámico en el que, por remitirnos a las categorías clásicas de la ciencia política, la legitimidad de ejercicio tenía un peso mayor que la de origen ${ }^{86}$.

Cabe preguntarse si esta conclusión a la que se ha llegado tras el análisis llevado a cabo en este artículo es extrapolable al segundo franquismo en términos generales. Es indudable que la legitimidad de origen en la que el régimen de Franco basaba su existencia, la victoria en la guerra civil, ocupó hasta el final de sus días un lugar central. Lo que aquí se propone es que el juego entre ésta y la de ejercicio fue cambiante, y en la segunda mitad de la dictadura el balance entre una y otras fue más equilibrado. Prueba de ello son los intentos por parte de Falange de racionalizar y modernizar el sistema de vacaciones que este artículo ha mostrado. La obra de Gutiérrez del Castillo ha de entenderse desde

${ }^{85}$ Carta de Bonifacio García Duarte a José María Gutiérrez del Castillo, 28.7.1959, AGA, 006.005.01, caja 15145.

${ }^{86}$ BOBBIO, 1984. 
este prisma, el asegurar que el funcionamiento de una actividad como las vacaciones, que se ha extendido a amplias capas de la población en muchos países europeos, sea satisfecha también en el caso de los españoles. El caso de Educación y Descanso muestra algunos éxitos parciales, pero, sobre todo, los límites del modelo dictatorial, en el que los privilegios económicos, políticos y sociales de los vencedores de la guerra habían adquirido una dimensión lo suficientemente sólida como para que ni siquiera el Movimiento pudiera aplacarlos.

A pesar de ello, también se ha visto cómo los individuos que carecían de estos privilegios eran capaces de idear estrategias para conseguir objetivos concretos. Estas pasaban por aludir a algunos de los pilares ideológicos y morales del régimen, como era la caridad, para exigir que sus necesidades se vieran colmadas. Las críticas a los privilegios, la invención de enfermedades como reclamo, y la exigencia de cumplir las propias normas que el Movimiento había firmado muestran una amplitud de subjetividades que nos invitan a repensar el rol del individuo bajo el franquismo no como una figura pasiva y subyugada, sino activa, dinámica y con gran capacidad para intervenir en su medio. El caso de las vacaciones que aquí se ha mostrado se une a una ya interesante cantidad de aportaciones en este sentido que nos obligan a reconceptualizar el funcionamiento de la dictadura, teniendo en cuenta de forma abierta la interacción entre las instituciones y los sujetos.

\section{BibliogRAFía}

Amaya Quer, Alex, El acelerón sindicalista. El aparato de propaganda de la Organización Sindical Española entre 1959 y 1969, Madrid, Centro de Estudios Políticos y Constitucionales, 2013.

Amilivia, José Maria, Emilio Romero. El gallo del franquismo, Madrid, Temas de Hoy, 2005.

Bobbio, Norberto, Origen y Fundamentos del poder político, México DF, Grijalbo, 1984.

Broszat, Martin (coord.), Bayern in NS-Zeit, Munich / Viena, R. Oldenbourg, 19771983.

Butterfield, Herbert, Butterfield y la razón histórica: la interpretación Whig de la Historia, introducción, traducción y comentarios de Rocío Orsi, Madrid, Plaza y Valdés, 2013.

Carcelén González, Ricardo, Cuando la clase obrera se hizo turista. Estudio de un modelo inacabado 1955-1975, tesis doctoral inédita, Universidad de Cartagena, 2017.

Cenarro, Ángela, «La Historia desde abajo del Franquismo», en Oscar Rodríguez Barreira (coord.), El franquismo desde los márgenes: campesinos, mujeres, delatores, menores, Almería, Editorial de la Universidad de Almería, 2013: 29-44. 
Crumbaugh, Justin, Destination Dictatorship: The Spectacle of Spain's Tourist Boom and the Reinvention of Difference, Nueva York, Suny Press, 2009.

Díaz Bello, María, «En busca del obrero: la organización del consentimiento en la España franquista» en Miguel Ángel Ruiz Carnicer y Carlos Frías Corredor (coords.), Nuevas tendencias historiográficas e historia local en España: actas del II Congreso de Historia Local de Aragón (Huesca, 7 al 9 de julio de 1999), Zaragoza, Instituto de Estudios Altoaragoneses / Universidad de Zaragoza, 2001: 241253.

Fuentes Quintana, Enrique, «El plan de Estabilización Económica de 1959: veinticinco años después», Información Comercial Española: Revista de Economía, 162-163 (Madrid, 1984): 25-40.

Fuertes Muñoz, Carlos, Viviendo en dictadura. La evolución de las actitudes sociales hacia el franquismo, Granada, Comares, 2017.

Geremek, Bronislaw, La piedad y la horca: historia de la miseria y de la caridad en Europa, Madrid, Alianza, 1989.

Gil Pecharromán, Julio, Con permiso de autoridad: La España de Franco (19391975), Barcelona, Temas de Hoy, 2008.

Ginzburg, Carlo, El queso y los gusanos. El cosmos de un molinero del siglo XVI, Madrid, Ediciones Península, 2016.

Glaser, Moritz, Wandel durch Tourismus. Spanien als Strand Europas, 1950-1983, Hamburgo, UVK, 2018.

González Martín, Damián Alberto, «El segundo franquismo (1939-1976)», en Manuel Ortiz Heras (coord.), Historia Contemporánea de España (Siglo XX). Del desastre del 98 a la crisis sistemática actual, Madrid, Albatán, 2018: 285-314.

Hachtmann, Rudiger y Reichardt, Sven (coords.), Detlev Peukert und die NS-Forschung, Göttingen, Wallstein Verlag, 2015.

Hernández Burgos, Claudio, Franquismo a ras de suelo. Zonas grises, apoyos sociales y actitudes durante la dictadura (1936-1976), Granada, Editorial Universidad de Granada, 2013.

Hernández Burgos, Claudio, «Más allá del consenso y la oposición: las actitudes de la "gente corriente" en regímenes dictatoriales. Una propuesta de análisis desde el régimen franquista», Revista de Estudios Sociales, 50 (Bogotá, 2014): 87-100.

Hernández Burgos, Claudio, Fuertes Muñoz, Carlos y Del Arco, Miguel Ángel (coords.), No solo miedo. Actitudes políticas y opinión popular bajo la dictadura franquista (1936-1977), Granada, Comares, 2014.

Hispán Iglesias de Ussel, Pablo, La política en el régimen de Franco entre 1957 y 1969. Proyectos, conflictos y luchas por el poder, Madrid, Centro de Estudios Políticos y Constitucionales, 2006.

Jiménez Martínez, Lorién, La construcción política del turismo durante el franquismo, tesis doctoral inédita, Universidad de Zaragoza, 2014.

Kershaw, Ian, Popular Opinion and Political Dissent in the Third Reich: Bavaria 1933-1945, Oxford, Oxford University Press, 2002.

Koselleck, Reinhart, Futuro pasado. Para una semántica de los tiempos históricos, Barcelona, Paidós Ibérica, 1993. 
Lindenberger, Thomas, «Die diktatur der Grenzen. Zur einleitung», en Thomas Lindenberger (ed.), Herrschaft und Eigen-sinn in der Diktatur. Studien zur gesellschaftsgeschichte der DDR, Colonia / Weimar / Viena, Böhlau, 1999: 14-45.

López Gallegos, Silvia, «El control del ocio en Italia y España: De la Opera Nazionale Dopolavoro a la Obra Sindical de Educación y Descanso», Investigaciones históricas: Época moderna y contemporánea, 24 (Valladolid, 2004): 215-236.

Lüdtke, Alf, «Einleitung: Was ist und wer treibt Alltagsgeschichte?», en Alf Lüdtke (ed.), Alltagsgeschichte. Zur Rekonstruktion historischer Erfahrungen und Lebensweisen, Frankfurt / New York, Campus Verlag, 1989: 9-48.

Lüdtke, Alf, Eigen-sinn. Fabrikalltag, Arbeiterfahrungen und Politik vom Kaiserreich bis in dem Faschismus, Hamburg, Ergebnisse Verlag, 1993.

Marín Gómez, Isabel, «Reclamando la autonomía social y los derechos fundamentales: “ ¡Ni paternalismo ni caridad!”. Las asociaciones de asistencia social, discapacidad y salud y enfermedad en el franquismo y la transición española a la democracia (Murcia, 1964-1986)», La Razón Histórica, 34 (Murcia, 2016): 158187.

Minardi, Adriana, «El franquismo a la luz de sus metáforas», Cultura, Lenguaje y Representación. Revista de estudios culturales de la Universitat Jaume I, IX (Castellón, 2011): 117-133.

Molinero, Carme, La captación de las masas. Politica social y propaganda en el Régimen Franquista, Madrid, Cátedra, 2005.

Moreno Garrido, Ana, Historia del Turismo en España en el siglo XX, Madrid, Síntesis, 2007.

Muñoz Soro, Javier, “"Presos de las palabras”. Republicanismo y populismo falangista en los años sesenta», en Miguel Ángel Ruiz Carnicer (ed.), Falange. Las culturas políticas del fascismo en la España de Franco, 1936-1975), Zaragoza, Instituto Fernando el Católico, 2013: 343-365.

Niethammer, Lutz (coord.), «Die Jahre Weiss man nicht, wo man die heute hinsetzen soll: Faschismuserfahrungen im Ruhrgebiet», Berlin, Verlag J.H.W. Dietz, 1983.

Niethammer, Lutz, Wierling, Dorothee y Von Plato, Alexander, Die Volkseigene Erfahrung, Eine Archäologie des Lebens in der Industrieprovinz der DDR. 30 biographische Eröffnungen, Berlin, Rowohlt, 1991.

Nolte, Paul, Hans-Ulrich Wehler. Historiker und Zeitgenosse, Múnich, C.H. Beck, 2015.

Núñez Rivero, Cayetano y Núñez Martínez, Juan Jacobo, «La iglesia y la Falange», Revista de Derecho UNED, 19 (Madrid, 2016): 183-200.

Orbach, Danny, «Criticism Reconsidered: The German Resistance to Hitler in Critical German Scholarship», Journal of Military History, 75/2 (Virginia, abril 2011): 523566.

Pack, Sasha, La invasión pacífica: los turistas y la España de Franco, Madrid, Turner, 2009.

Pellejero, Carmelo (coord.), Historia de la economía del turismo en España, Madrid, Civitas, 1999.

Pérez Díaz, Víctor, El retorno de la sociedad civil, Madrid, Instituto de Estudios Económicos, 1987. 
Pons, Anaclet y Serna, Justo, «Cómo se escribe la microhistoria. Ensayo sobre Carlo Ginzburg», Madrid, Cátedra, 2000.

Rodríguez Barreira, Óscar, Migas con miedo. Prácticas de resistencia al primer franquismo. Almería, 1939-1953, Almería, Editorial Universidad de Almería, 2008.

Saz, Ismael (coord.), El franquismo en Valencia: formas de vida y actitudes sociales en la posguerra, Valencia, Episteme, 1999.

Saz, Ismael, España contra España: los nacionalismos franquistas, Madrid, Marcial Pons, 2003.

Soto Carmona, Álvaro, ¿Atado y bien atado? Institucionalización y crisis del franquismo, Madrid, Biblioteca Nueva, 2005.

Steinbach, Peter, Widerstand gegen die nationalsozialistische Diktatur 1933-1945, Bonn, Bundeszentrale für Politische Bildung, 2004.

Thomas, Joan Maria, Franquistas contra Franquistas. Luchas por el poder en la cúpula del Régimen de Franco, Barcelona, Debate, 2016.

Thompson, Edward Palmer, Miseria de la teoría, Barcelona, Crítica, 1981.

Townson, Nigel (coord.), España en cambio, el segundo Franquismo. 1959-1975, Madrid, Siglo XXI de España, 2009.

Turner, Louis y Ash, John, The Golden Hords. International tourism and the pleasure periphery, Nueva York, St' Martin Press, 1976.

Velasco, María, La política turística: gobierno y administración turística en España (1952-2004), Valencia, Tirant lo Blanch, 2004.

Recibido: 22/10/2019

Aceptado: 9/09/2020 